\title{
Role of CT Scan in Early Diagnosis of Temporomandibular Joint Injury in Patients with Rheumatoid Arthritis
}

\author{
Samia M AL-shaer
}

\begin{abstract}
A BSTRACTVN
Aims and objectives: Early detection of rheumatoid injury in the temporomandibular joint using CT, which accurately detects bone changes before the clinical symptoms start appearing to protect the joint from irreversible damage, and the correlation of those radiological changes with the duration of rheumatoid arthritis disease.

Materials and methods: It included 45 people aged 27-74 years who reviewed the internal medicine and rheumatology clinics at Al-Mouwasat Hospital during 2016-2018 and are affected with rheumatoid arthritis according to the criteria American College of Arthritis (ACR) European League against Rheumatism (EULAR) 2010 criteria. The informed consent of the patient and the approval of the Scientific Research Council were obtained to conduct the research.

Results: Computed tomography revealed the radiological changes in the left and right side, respectively, in terms of $p$ value $<0.05$ : (1) Erosion of condyle (42.22-53.34\%). (2) Decreased in the joint space (53.33-60.00\%). (3) Mandibular subchondral cysts in both sides (77.14\%). (4) Erosion of the articular fossa (48.89-57.78\%). (5) Flattening of condyle (46.67-55.55\%). (6) Effusion (2.22-4.44\%). (7) Bone marrow edema (26.67-40.00\%). (8) Subchondral sclerosis (60.00-73.33\%).

Conclusion and clinical significance:The occurrence of bone damage in the condyle and articular fossa of the temporomandibular joint despite the fact that the sample members have no clinical complaint indicates the ability of CT scan of early and accurate disclosure of rheumatoid injury in the temporomandibular joint.

Keywords: Computed tomography, Rheumatoid arthritis, Temporomandibular joint MRI.

The Journal of Contemporary Dental Practice (2020): 10.5005/jp-journals-10024-2868
\end{abstract}

\section{INTRODUCTION}

Temporomandibular joint (TMJ) is considered one of the most important and used joints in humans. It works continuously-even if a person stops eating and talking - the physiological swallowing process continues all day long.

However, this vital and significant joint is exposed to many diseases directly or as a result of different diseases that affect the person, and then their effects are transmitted to it such as gout, lupus erythematosus, diabetes, and osteoporosis. Among the serious diseases that affect the TMJ is rheumatoid arthritis (RA); it is a very severe, chronic, inflammatory disease, disfiguring and damaging to the joints. It is also a systemic disease that affects the entire body and not just a localized disease to the joints but rather a life-threatening disease that leads to shortening the lifespan for 3-18 years and leads to complete deficiency in about $50 \%$ of the patients 10 years after the disease starts and to full disability after 20 years in $90 \%$ of the patients. ${ }^{1-4}$

Doctors are usually concerned with all body joints in rheumatoid disease patients and usually disregard the evaluation of the TMJ, which is also affected with RA. Several studies have shown that approximately $50-75 \%$ of patients with RA are found to have a following TMJ injury. 5,6

Also, the injury can be silent, or it could be the only joint affected with RA. ${ }^{7,8}$ Rheumatoid arthritis has symptoms and health complications that also affect the quality of life for the individual, but when the patient reaches the stage of the clinical complaint of TMJ pain, click, and swelling in front of the ear in addition to morning stiffness, the RA is in a late stage, the treatment is difficult, and the damage in the TMJ segments is irreversible. ${ }^{9}$ Although multiple radiographic diagnostics are used in evaluating the TMJ,
Faculty of Dentistry, Department of Oral Medicine, Damascus University, Damascus, Syria

Corresponding Author: Samia M AL-shaer, Faculty of Dentistry, Department of Oral Medicine, Damascus University, Damascus, Syria, Phone: +963944722797, e-mail: Dr.samiaalshaer@gmail.com

How to cite this article: AL-shaer SM. Role of CT Scan in Early Diagnosis of Temporomandibular Joint Injury in Patients with Rheumatoid Arthritis. J Contemp Dent Pract 2020;21(7):769-775.

Source of support: Damascus University

Conflict of interest: None

there are several ways to evaluate the TMJ by different radiological methods such as panoramic radiology, ${ }^{10}$ transcranial projection, ${ }^{11}$ echography, ${ }^{12}$ and magnetic resonance imaging (MRI). ${ }^{13-15}$ The use of computed tomography (CT) in diagnosing the TMJ disorders returns to the late $1980 s^{16,17}$ Computed tomography provides great image details about TMJ's bone deformities such as fractures, bone tumors, and bone pathological changes. As the two joints are combined together in one picture on a computer, this enhances the accuracy of diagnosing the disorders of the TMJ. ${ }^{18}$ Therefore, in this research, bone changes in the TMJ were studied using CT (helical or spiral), which is considered one of the available techniques that provide high-resolution imaging. It was known in the early 1900s and used the slip-ring technology. The scan time was decreased to several seconds, the radiation dose was reduced to about $75 \%$, and the data from spiral allowed for $3 \mathrm{D}$ reconstruction. ${ }^{19}$ It is provided with specialized programs for assessing bone density and thus digitally assessing bone quality (quantify of bone quality). ${ }^{20}$

This radiological study using CT aims to investigate the radiographic changes that affect the TMJ in patients with RA early 
and accurately before the clinical complaint begins to protect the joint from irreversible bone damage and study the correlation between those radiological changes and the duration of RA injury.

\section{Materials and Methods}

Cross-sectional and analytical study and observational study of patients who reviewed the internal medicine and rheumatology clinics at Al-Mouwasat University Hospital during January (2016) to April (2018).

\section{Inclusion Criteria}

Patients who were reviewed at the rheumatology clinic at the $\mathrm{Al}$ Mouwasat Hospital who had general diagnosis of RA over the age of 18 and whose conditions met the new standards established in 2010 by the American College of Arthritis (ACR) and European Association for Rheumatology (EULAR) were examined. ${ }^{21}$

Their medical history and medications were taken. Clinical examination of the mouth and jaws was done. We excluded the patients with the following clinical symptoms, which are considered clinical criteria for the progressive disease: swelling around the joint, pain, tenderness on pressure, and morning stiffness of the joint that lasts for more than 10 minutes. ${ }^{22}$

We also excluded the patients who had conservations about the radiographic procedure (pregnancy, previous radiological treatments, etc.) and also those who have metal objects in their body (artificial joint, artificial valve, prostheses, etc.).

Patients who had other diseases that affect the joints' (ankylosing spondylitis, diabetes, osteoporosis, etc.). Furthermore, patients with joint disorders (articular disk displacement) or previous injures such as (trauma, fractures, etc.) were excluded.

We had 67 patients who met the inclusion criteria. We randomly selected 50 of them, and 3 of those patients dropped out of the study for personal causes and 2 were excluded due to the development of an obvious clinical complaint, so the sample of the study became 45 patients. The study sample individuals ranged in age from 27 to 74 years, with a mean of $(48.45 \pm 14.92)$ years.

Treatment of each case was determined by the rheumatologist according to each patient history and case. This study is not about the treatment of each patient and the effect of the treatment used on their case.

Informed consent of the patients was obtained. Ethical approval for the research was obtained from the University's Scientific Research Council.

\section{Radiographic Examination for the TMJ}

Ninety TMJs for 45 patients participating in the study were studied using a high-resolution computed spiral tomography (HRCT) (Astein VF, Toshiba, and Japanese), located in the Radiological Division of Al Mouwasat Hospital by conducting thin axial and coronal sections $(2 \mathrm{~mm}){ }_{1}^{23}$ without contrast, using closed mouth position. Since we excluded every patient who had articular disk displacement or clicking, we did not perform the dynamic study nor a study of articular disc status.

Radiographs were read by the researcher and radiologist at the Al Mouwasat Hospital. It was re-evaluated again after two weeks, also in some cases that were not conclusive for a radial variable, these cases were reviewed by a third radiologist. The radiologists would examine the CT scans without any personal details about the patients. The author and a radiologist examined the CT scans, and in cases of doubt, opinion from a third radiologist was taken.
The following radiological changes were studied at level $p$ value $<0.05$ and were shown by CT scan (Table 1):

- Erosion of condyle

- Decrease in the joint space

- Mandibular subchondral cysts

- Erosion of the articular

- Flattening of condyle.

Table 1: Definition of CT pathological lesions in rheumatoid arthritis

\begin{tabular}{ll}
\hline Radiological changes & Description \\
\hline 1. Erosion of condyle & Bone damage appears \\
& radiologically as a focal area, \\
& where the density decreases at \\
& the cortical edge of the articular \\
& surface of the mandible and the \\
& subchondral region as shown in \\
& Figure $1 \mathrm{~A} .{ }^{24}$
\end{tabular}

2. Decreased in the joint space The articular distance is the distance between the maxillary condyle and the pelvic cavity and is approximately $2 \mathrm{~mm}$ in the normal state as shown in Figure $1 \mathrm{~B}^{25}$

3. Mandibular subchondral cysts Subchondral bone cysts are sacs of fluid that form inside a person's joints. The cysts occur in the subchondral bone, the layer of bone just under the cartilage (Fig. 2A). ${ }^{26}$

4. Erosion of the articular fossa Bone erosion A sharply margin lesion with correct juxtaarticular location and typical signal changes, with visibility in 2 planes and cortical break in at least one plane (Fig. 2B). ${ }^{27}$

5. Flattening of the condyle

In general, the mandibular condyle is convex at the frontal plane and extremely convex in the sagittal plane, but the bone around it flattens, deviating it from the convex shape and becoming flat due to chronic inflammatory bones diseases (Fig. 3A). ${ }^{28}$

6. Effusion Joint effusion represents an abnormally large accumulation of intra-articular fluid and is commonly seen in symptomatic patients. A small amount of joint fluid can be seen in asymptomatic patients (Fig. 3B). ${ }^{29}$

7. Bone marrow edema Bone edema: A lesion within the trabecular bone with ill-defined margins and signal characteristics of increased water content (Fig. 4A). ${ }^{27}$

8. Subchondral sclerosis It appears as a high-density region on radiography. Subcutaneous sclerosis may be caused by bone diseases, such as osteoporosis and rheumatoid arthritis, as shown in Figure 4B. ${ }^{30}$ 

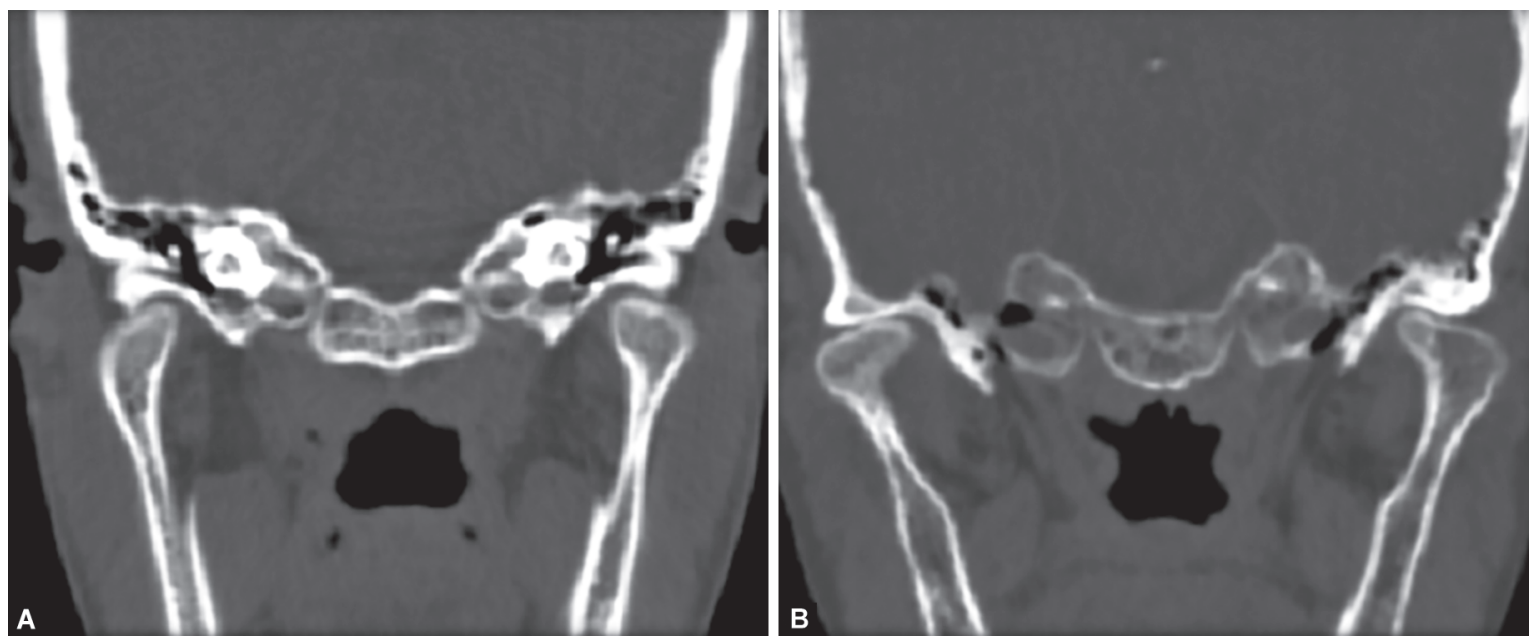

Figs $1 \mathrm{~A}$ and B: (A) Coronal computed tomography (CT) scan showing erosion of condyle in temporomandibular joint (TMJ) on both sides; (B) Coronal CT scan showing reduction in joint space in TMJ on both sides

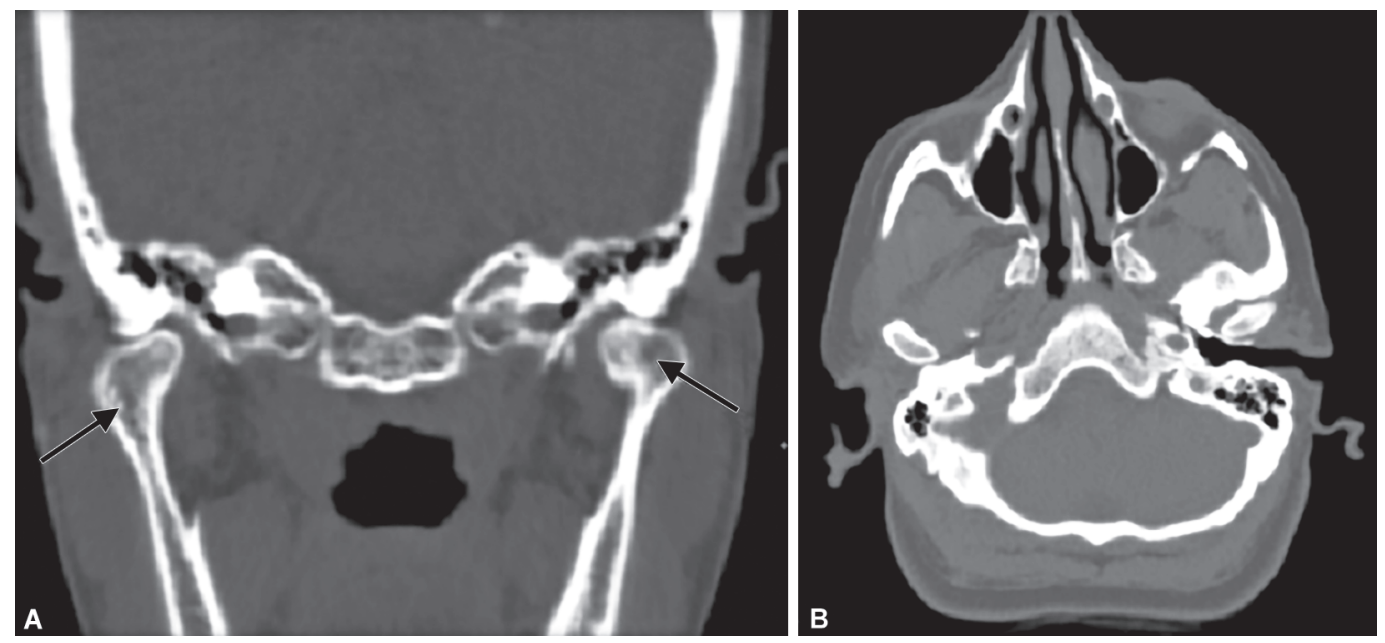

Figs 2A and B: (A) Coronal computed tomography (CT) scan showing mandibular subchondral cysts in temporomandibular joint (TMJ) on both sides; (B) Coronal CT scan showing erosion of the articular fossa in TMJ on the left side
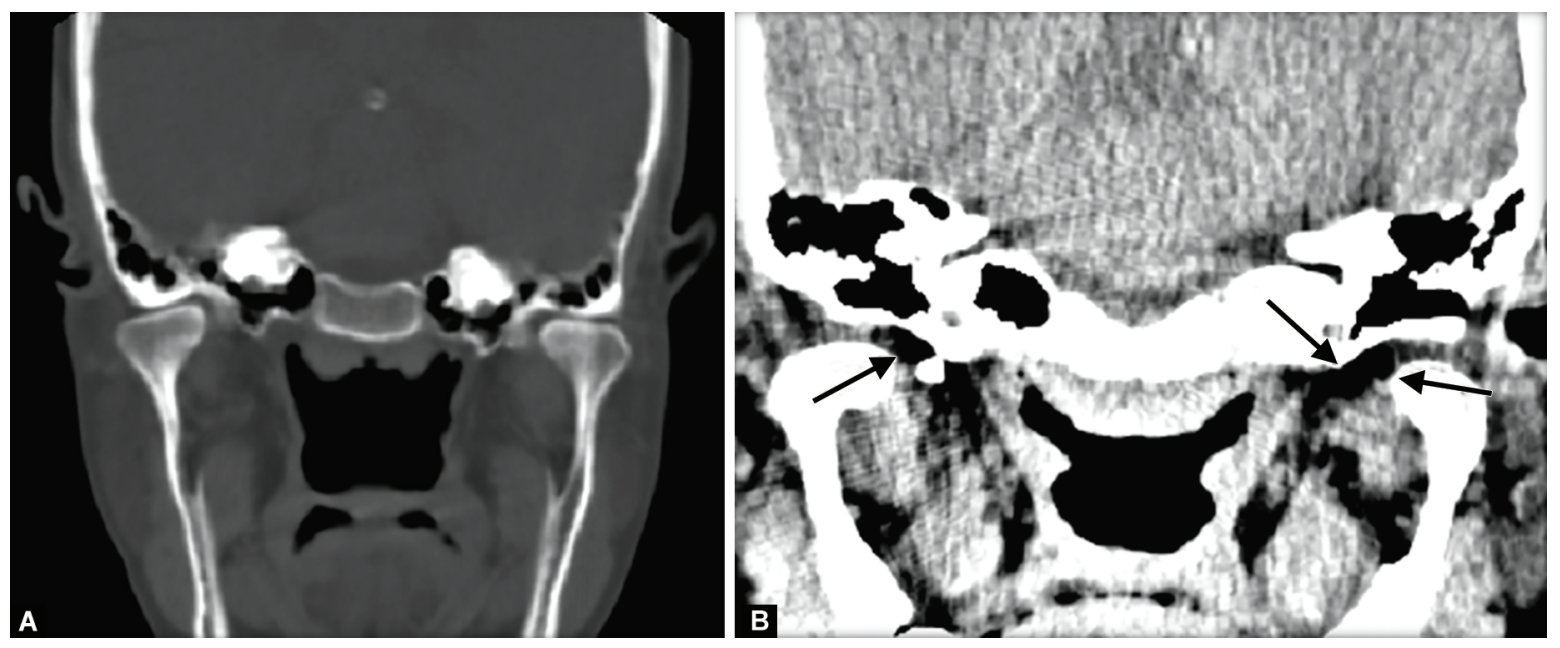

Figs $3 \mathrm{~A}$ and $\mathrm{B}$ : (A) Coronal computed tomography (CT) scan showing flattening of condyle in temporomandibular joint (TMJ) on both sides; (B) Coronal CT scan (soft tissues window) showing effusion in TMJ on both sides 

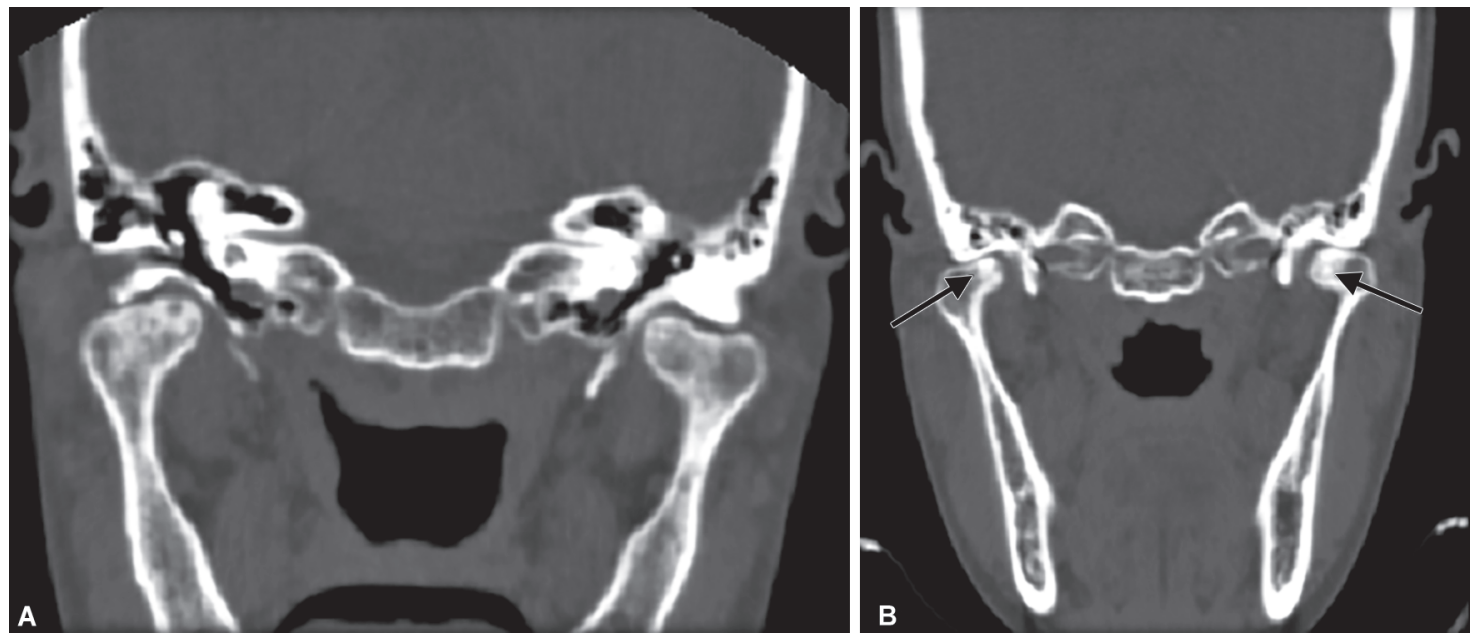

Figs 4A and B: (A) Coronal computed tomography (CT) scan showing bone marrow edema in temporomandibular joint (TMJ) on both sides; (B) Coronal CT scan showing subchondral sclerosis in TMJ on both sides

- Effusion

- Bone marrow edema

- Subchondral sclerosis.

\section{Statistical Study}

Statistical analysis was performed using Microsoft Excel, where the mean and standard deviation of the studied variables were calculated, the variables were compared using the Chi-square test at $p$ value $\leq 0.05$, and the data were processed using the SPSS. ${ }^{20}$

\section{Results}

\section{Description of the Study Sample}

The sample of the study was divided into males and females as shown in Table 2 in different ratios, where the percentage of the male study sample reached $17.78 \%$ compared to $82.22 \%$ females. The age of the study sample ranged from 27 to 74 years, with an average of $48.45 \pm 14.92$ years. The duration of RA disease ranged from 1 to 25 years in the individuals of the sample as shown in Table 3 with a mean duration of disease $10 \pm 6.752$ years. The percentage of those affected for less than 5 years was $28.75 \%$, and those who were affected between 5 years and 10 years was $31.43 \%$, compared to $40.0 \%$ who were affected for more than 10 years.

The patients were distributed into the following age-groups: those aged younger than 40 (28.89\%), those aged $40-60$ years $(42.22 \%)$, and those aged older than 60 years (28.89\%), which was concurrent with a similar study. ${ }^{24}$

\section{Results of the Radiological Study}

Table 4 shows the relative distribution of radiological changes revealed by CT scan of the TMJ.

- Erosion of condyle (42.22-53.34\%).

- Decreased in the joint space (53.33-60.00\%).

- Mandibular subchondral cysts in both sides (77.14\%).

- Erosion of the articular fossa (48.89-57.78\%).

- Flattening of condyle (46.67-55.55\%).

- Effusion (2.22-4.44\%).
Table 2: Sample specification shows the repetitive and relative distribution according to gender and age

\begin{tabular}{lllc}
\hline & & Frequency & Percent \\
\hline Gender & Male & 8 & 17.78 \\
& Female & 37 & 82.22 \\
& Total & 45 & 100 \\
\multirow{4}{*}{ Age } & $<40$ & 13 & 28.89 \\
& $40-60$ & 19 & 42.22 \\
& $>60$ & 13 & 28.89 \\
& Mean \pm Std. deviation & $(48.45 \pm 14.92)$ & \\
\hline
\end{tabular}

Table 3: Repetitive and relative distribution of the sample members according to the injury duration variable

\begin{tabular}{lrlr}
\hline & & Frequency & Percent \\
\hline Duration & $0-5$ & 13 & 28.89 \\
& $5-10$ & 14 & 31.11 \\
& $>10$ & 18 & 40.00 \\
& Total & 45 & 100.00 \\
\hline
\end{tabular}

- Bone marrow edema (26.67-40.00\%).

- Subchondral sclerosis (60.00-73.33\%).

The most frequently found changes were mandibular subchondral cysts, subchondral sclerosis, flattening of condyle, and decreased joint space. the less frequent changes included effusion and bone marrow edema. Almost half of the patients had condyle and articular fossa erosion.

\section{Results of the Correlation between Radiological Changes and the Chronicity of the Disease}

Table 5 shows the results of Chi-square test for the correlation between the scanning method and the duration for RA disease in which $p$ value was $>0.05$ on the left side (0.16) and on the right side (0.29). This indicates that there is no statistically significant correlation between the results of CT diagnosis of the TMJ and the duration that has elapsed since the diagnosis of RA in the research sample. 
Table 4: Repetitive and relative distribution of radiographic changes with CT for the temporomandibular joint in those with rheumatoid disease

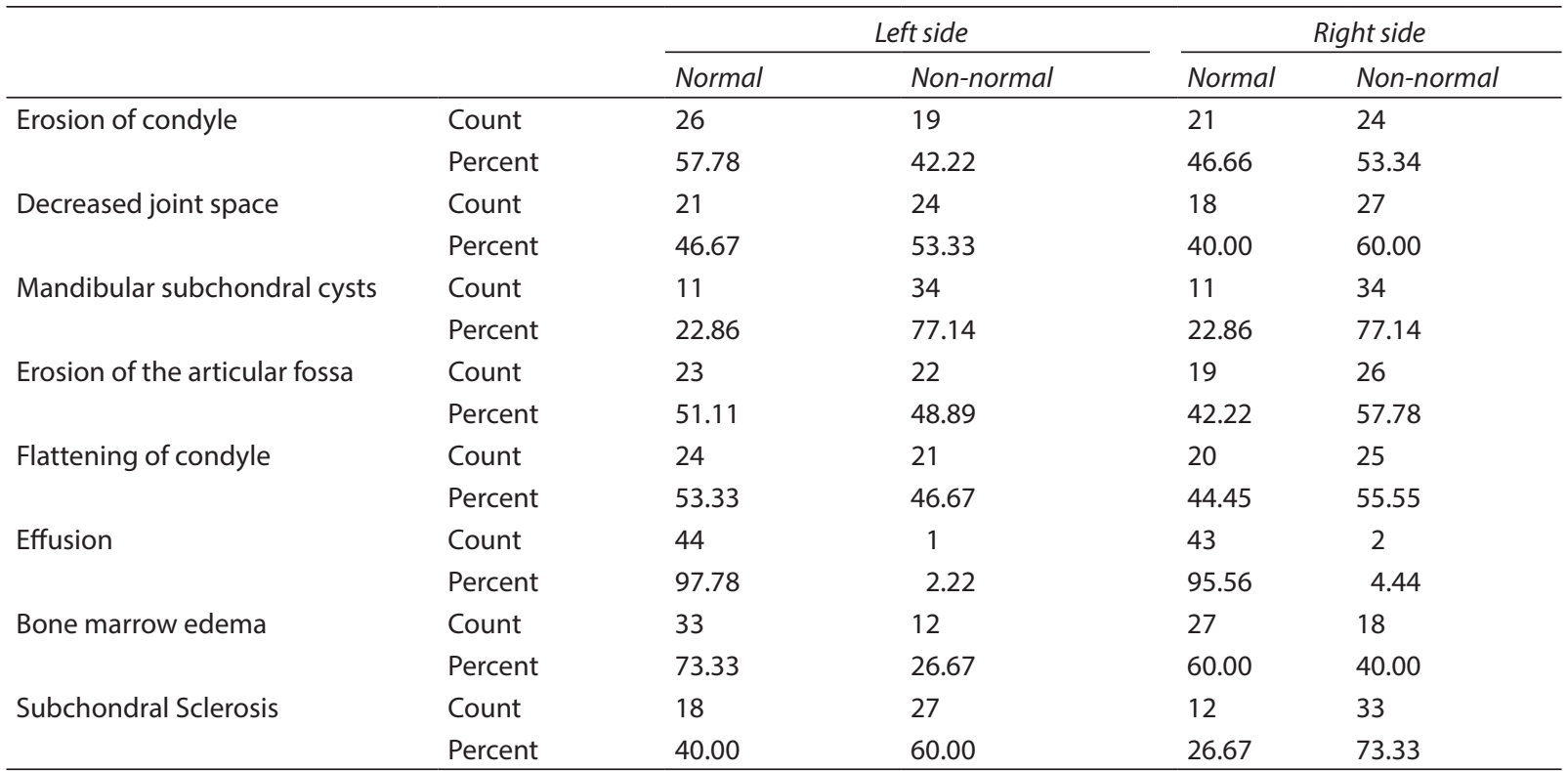

Table 5: Repetitive and relative distribution of scanning method (CT), the duration elapsed since rheumatoid disease diagnosis, and the results of the Chi-square test for the correlation between radiography and the duration of rheumatoid disease injury

\begin{tabular}{|c|c|c|c|c|c|c|c|c|}
\hline & & & \multicolumn{3}{|c|}{ Duration } & \multirow[b]{2}{*}{ Total } & \multicolumn{2}{|c|}{ Chi-square test } \\
\hline & & & $0-5$ & $5-10$ & $>10$ & & Value & $p$ value \\
\hline \multirow[t]{4}{*}{ CT Left side } & Normal & Count & 6 & 4 & 3 & 13 & 3.66 & 0.16 \\
\hline & & Percent & 13.33 & 8.89 & 6.67 & 28.89 & & \\
\hline & Non-normal & Count & 6 & 10 & 16 & 32 & & \\
\hline & & Percent & 13.33 & 22.22 & 35.56 & 71.11 & & \\
\hline \multirow[t]{2}{*}{ Total } & & Count & 12 & 14 & 19 & 45 & & \\
\hline & & Percent & 26.67 & 31.11 & 42.22 & 100.00 & & \\
\hline \multirow[t]{4}{*}{ CT Right side } & Normal & Count & 4 & 4 & 2 & 10 & 2.44 & 0.29 \\
\hline & & Percent & 8.89 & 8.89 & 4.44 & 22.22 & & \\
\hline & Non-normal & Count & 9 & 10 & 16 & 35 & & \\
\hline & & Percent & 20.00 & 22.22 & 35.56 & 77.78 & & \\
\hline \multirow[t]{2}{*}{ Total } & & Count & 13 & 14 & 18 & 45 & & \\
\hline & & Percent & 28.89 & 31.11 & 40.00 & 100.00 & & \\
\hline
\end{tabular}

\section{Discussion}

The participants in our research did not have clinical complaint about TMJ; however, radiographic changes were present in all patients and in different percentages as shown in Table 1. This is an important result that directs the healthcare workers to focus on examining the TMJ clinically and conducting CT scans in every patient with RA to inspect secondary rheumatoid injury that can be silent and asymptomatic to save the joint from disruption. This result is similar to Larheim, ${ }^{31}$ which confirmed that there is no correlation between clinical symptoms and radiological findings when examining patients with RA using CT. Holmlund ${ }^{32}$ also confirmed that there is no correlation between clinical symptoms and radiological findings in CT scans of the TMJ in patients with RA.

Table 1 shows eight pathological radiological changes that occurred in the TMJ, usually associated with RA. The most frequent findings were the mandibular subchondral cysts, subchondral sclerosis, flattening of condyle, articular distance decreasing in addition to condylar erosion, erosion of the articular fossa, and less frequent findings were effusion and bone marrow edema, which indicates that CT scan is able to detect detailed bone changes that damage the TMJ joint due to RA. This is similar to Sinha study, ${ }^{33}$ which showed that the CT scan provides accurate information about changes in the joint's solid tissues. The result of this research was also similar to Celiker study, ${ }^{34}$ which confirms that CT scan is sensitive to evaluate early abnormal changes in the TMJ in RA patients. The current research was also similar to a study done by Goupille and his colleagues, ${ }^{35}$ where bone changes were detected by $C T$ and relied on the description of erosion and cyst formation in the condyle in which these findings were considered descriptive for RA. Other findings included temporomandibular fossa erosion and narrowing of articular distance. These radiological findings are compatible with the findings of our research. ${ }^{36}$ 
In Bag et al. study, ${ }^{24}$ visualizing the TMJ was highlighted to understand the many diseases that may affect it, and they concluded that CT scan should be chosen to assess the TMJ when suspected with TMJ damage.

Bayar et al. study ${ }^{23}$ conducted a study using HRCT as a predictive sensor to detect TMJ injury in patients with RA, and before the occurrence of clinical symptoms, it was found that $46.7 \%$ of the patients had pathological findings in the TMJ on HRCT and had no clinical symptoms, despite the laboratory tests confirmed that they had RA.

Bayar et al. ${ }^{23}$ results were similar to this research that all patients have different percentages of pathological radiological findings in the TMJ, at least with two radiological changes, and this is explained by several reasons:

- Because some patients delay seeking treatment from a specialized rheumatology doctor and thus delay the correct diagnosis of the disease.

- Also, even when referring to a specialist, he does not direct patients to see a specialized dentist, and the consult of the TMJ is ignored, especially in the absence of clinical symptoms in the joint as in this research sample.

- The lack of adherence of some patients in taking their prescribed medication and their adherence in taking analgesics, which relieve symptoms such as pain and edema, which leads to the continuation of the inflammatory and TMJ injury.

- Some patients do not take the medication regularly, trying to avoid the side effects of RA medicines, which also leads to aggravation of the medical condition.

In Table 5, the value of the statistical significance of the left and right sides, respectively, was 0.29 and 0.16 which is greater than the level of the statistical significance $(\alpha=0.05)$; therefore, there is no statistically significant relation between the scanning method (CT) in the left and right sides and the duration of RA disease at the statistical significance level $(\alpha=0.05)$.

This is similar to Witulski study ${ }^{22}$ that did not find a relation between joint destruction and the disease chronicity, which gives importance to early radiological examination to detect the bone damage in the TMJ, which allows us to start disease-modifying treatment earlier. But this result was different from Syrjanen research, ${ }^{37}$ which found that joint lesions increased with longer RA disease duration.

\section{Conclusion and Clinical Significance}

The detection of bone damage of the condyle and articular fossa of the TMJ in the research individuals with rheumatoid disease with CT scan, despite the absence of clinical symptoms in the TMJ, indicates that CT scan is important to detect rheumatoid injury at an earlier stage in the TMJ in asymptomatic patients, which helps them obtain effective treatment that protects their joints from irreversible damage.

The research also concluded that there is no statistically significant relation between the occurrence of radiological disruption in the TMJ and the duration of the RA at $(\alpha=0.05)$.

\section{Suggestions}

Setting criteria to assist early radiographic diagnosis of TMJ injury with RA and to develop a protocol that helps radiologists, rheumatologists, and dentists in choosing the appropriate medical scanning technique.

\section{Recommendations}

We recommend examining the TMJ and performing a CT scan for every patient with RA in order to early detect bone changes so that we can prevent injury progression through adjusting treatment and periodic monitoring.

\section{Limitations of the Study}

Computed tomography scan does not show all the bone changes in RA patients.

\section{References}

1. Choy EH, Panayi GS. Cytokine pathways and joint inflammation in rheumatoid arthritis. N Engl J Med 2001;344(12):907-916. DOI: 10.1056/NEJM200103223441207.

2. Chen S, Gill MA, Luu CH, et al. Pain and rheumatoid arthritis: an update. Drug Topics 2000;3:47-56.

3. Pincus T. Advantages and limitations of quantitative measures to assess rheumatoid arthritis: joint counts, radiographs, laboratory tests, and patient questionnaires. Bull NYU Hosp Jt Dis 2006; 64(1-2):32-39.

4. Scott DL, Shipley M, Dawson A, et al. The clinical management of rheumatoid arthritis and osteoarthritis: strategies for improving clinical effectiveness. Br J Rheumatol 1998;37(5):546-554. DOI: 10.1093/rheumatology/37.5.546.

5. Helenius LMJ, Tervahartiala P, Helenius I, et al. Clinical, radiographic and MRI findings of the temporomandibular joint in patients with different rheumatic diseases. Int J Oral Maxillofac Surg 2006;35(11):983-989. DOI: 10.1016/j.ijom.2006.08.001.

6. Koh ET, Yap AU, Koh CK, et al. Temporomandibular disorders in rheumatoid arthritis. J Rheumatol 1999;26(9):1918-1922.

7. Hu YS, Schneiderman ED, Harper RP. The temporomandibular joint in juvenile rheumatoid arthritis: part II. Relationship between computed tomographic and clinical findings. Pediatr Dent 1996;18(4):312-319.

8. Svensson B, Adell R, Kopp S. Temporomandibular disorders in juvenile chronic arthritis patients. A clinical study. Swed Dent $J$ 2000;24(3):83-92.

9. Yoshida A, Higuchi $Y$, Kondo $M$, et al. Range of motion of the temporomandibular joint in rheumatoid arthritis: relationship to the severity of disease. Cranio 1998;16(3):162-167. DOI: 10.1080/08869634.1998.11746054.

10. McNeill C. Science and practice of occlusion. 1st ed. U S A Quintessence Books 1997. 538.

11. Langland OE, Langlais RP, Preece JW. Principles of Dental Imaging. 2th ed., Philadelphia: Williams \& Wilkins; 2002. 219-258.

12. Melchiorre D, Calderazzi A, Maddali Bongi S, et al. Comparison of ultrasonography and magnetic resonance imaging in the evaluation of temporomandibular joint involvement in rheumatoid arthritis and psoriatic arthritis. Rheumatology 2003;42(5):673-676. DOI: 10.1093/ rheumatology/keg181.

13. Tehranzadeh J, Ashikyan O, Dascalos J. Magnetic resonance imaging in early detection of rheumatoid arthritis. Semin Musculoskelet Radiol 2003;7(2):79-94. DOI: 10.1055/s-2003-41342.

14. McQueen FM, Benton N, Perry D, et al. Bone edema scored on magnetic resonance imaging scans of the dominant carpus at presentation predicts radiographic joint damage of the hands and feet six years later in patients with rheumatoid arthritis. Arthritis Rheum 2003;48(7):1814-1827. DOI: 10.1002/art.11162.

15. Radswiki, Gaillard Frank, Temporomandibular joint inflammation:N.D. (c) 2005-2017 Radiopaedia.org.

16. Holberg C, Steinhäuser $S$, Geis $P$, et al. Cone-beam computed tomography in orthodontics: benefits and limitations. J Orofac Orthop 2005;66(6):434-444. DOI: 10.1007/s00056-005-0519-z.

17. Miraclea AC, Mukherjia SK. Cone beam CT of the head and neck, part 1 : physical principles. Journal of Neuroradiology 2009;30(6):1088-1095. DOI: 10.3174/ajnr.A1653. 
18. Goswami R, Arora P, Gaba N, et al. Insights of TMJ through advanced imaging. Research 2015;6(01):1-7.

19. Goldman. LW. Principles of CT and CT technology. J Nucl Med Technol 2007;35(3):115-128. DOI: 10.2967/jnmt.107.042978.

20. Shapurian T, Damoulis PD, Reiser GM, et al. Quantitative evaluation of bone density using the Hounsfield index. Int J Oral Maxillofac Implants 2006;21(2):290-297.

21. Aletaha D, Neogi T, Silman AJ, et al. Rheumatoid arthritis classification criteria: an American college of rheumatology/European league against rheumatism collaborative initiative. Ann Rheum Dis 2010;69(9):1580-1588. DOI: 10.1136/ard.2010.138461.

22. Witulski S, Vogl TJ, Rehart S, et al. Evaluation of the TMJ by means of clinical TMD examination and MRI diagnostics in patients with rheumatoid arthritis. Biomed Res Int 2014;2014:328560. DOI: 10.1155/2014/328560.

23. Bayar N, Kara SA, Keles I, et al. Temporomandibular joint involvement in rheumatoid arthritis: a radiological and clinical study. Cranio 2002;20(2):105-110. DOI: 10.1080/08869634.2002.11746198.

24. Bag AK, GaddikeriS, Singhal A, etal.Imaging of the temporomandibular joint. World J Radiol 2014;6(8):567-582. DOI: 10.4329/wjr.v6.i8.567.

25. Greenberg MS, Glick M, Ship JA. Burket's Oral Medicine. 11th ed., India: BC Decker Inc Hamilton; 2008;9:223-255.

26. Subchondral bone cyst: Causes, treatment, and symptoms. Jayne Leonard. 17 August 2017, https://www.medicalnewstoday.com/ articles/318976.php

27. Wakefield RJ, Kong KO, Conaghan PG, et al. The role of ultrasonography and magnetic resonance imaging in early rheumatoid arthritis. Clin Exp Rheumatol 2003;31(5 Suppl 31):S42-S49.

28. Burde KN, Naikmasur VG, Sattur AP. Assessment of condylar changes in patients with temporomandibular joint pain using digital volumetric tomography: radiology research and practice. 2014;2014:106059.

29. Larheim TA, Katzberg RW, Westesson PL, et al. MR evidence of temporomandibular joint fluid and condyle marrow alterations: occurrence in asymptomatic volunteers and symptomatic patients. J Oral Maxillofac Surg 2001;30(2):113-117. DOI: 10.1054/ijom.2000. 0018.

30. https://www.verywell.com > Conditions > Osteoarthritis > Diagnosis.

31. Larheim TA, Tveito L, Dale K, et al. Temporomandibular joint abnormalities in rheumatoid arthritis: comparison of different radiographic methods. Acta Radiol Diagn (Stockh) 1981;22(6):703-707. DOI: $10.1177 / 028418518102200615$.

32. Holmlund AB, Gynther G, Reinholt FP. Rheumatoid arthritis derangement of the temporomandibular joint. Oral Surg Oral Med Oral Pathol 1992;73(3):273-277. DOI: 10.1016/0030-4220(92)90119-b.

33. Sinha VP, Pradhan H, Gupta H, et al. Efficacy of plain radiographs, CT scan, MRI and ultra sonography in temporomandibular joint disorders. Natl J Maxillofac Surg 2012;3(1):2-9. DOI: 10.4103/0975-5950.102138.

34. Celiker R, Gökçe-Kutsal Y, Eryilmaz M. Temporomandibular joint involvement in rheumatoid arthritis. relationship with disease activity. Scand Rheumatol 1995;24(1):22-25. DOI: 10.3109/03009749509095149.

35. Goupille P, Fouquet B, Cotty P, et al. Temporomandibular joint and rheumatoid polyarthritis. X-ray computed tomographic aspects. J Radiol 1992;73(4):253-261.

36. Kretapirom K, Okochi K, Nakamura S, et al. MRI characteristics of rheumatoid arthritis in the temporomandibular joint. Dentomaxillofac Radiol 2013;42(4):31627230. DOI: 10.1259/dmfr/31627230.

37. Syrjanen SM. The temporomandibular joint in rheumatoid arthritis. Acta Radio1 Diagn (Stockh) 1985;26(3):235-243. DOI: 10.1177/028418518502600302. 